\title{
MAGNETIC RESONANCE EXAMINATION OF TMJS FOLLOWING OPEN REDUCTION AND INTERNAL FIXATION USING RHOMBUS AND TWO MINIPLATES IN MANAGEMENT OF UNILATERAL SUBCONDYLAR FRACTURE
}

\author{
Yasser Nabil Helmy* and Heba Abdwahed Selim**
}

\begin{abstract}
The objective of this study was to present a prospective study to investigate TMJ following open of unilateral subcondylar fracture using MRI. 30 adult male patients with recent history of unilateral mandibular subcondylar fractures were included. Three groups based on the method management of the subcondylar fracture mandibular fracture. Group 1 comprised patients who had unilateral condylar fractures treated by open reduction and internal fixation of subcondylar fracture using 3D rhombus plate (Orthomed) Group 2 patients were treated by open reduction and internal fixation of subcondylar fracture using 2 mini plates. Group 3 Control group were treated patients had a unilateral condylar fracture treated by closed reduction. Magnetic resonance imaging was performed on the patients within 10 days from the primary injury. The same clinical examination, radiographic and magnetic resonance imaging were performed six months later. The result of this study demonstrate that,there was no statistically significant differences observed between the three treatment groups for parameters like age, gender, type and side of the fracture, mechanism of injury and incidence of associated injuries, post-operative occlusion and need for IMF There was a no statistically significant difference between the MRI findings in all groups.
\end{abstract}

KEY WORDS: Magnetic resonance, Open reduction, subcondylar fracture

\section{INTRODUCTION}

Temporomandibular joint (TMJ) injuries as a result to mandibular fractures are not investigated routinely. The damage caused to the intra-capsular structures of the joint are often overlooked. inappropriate management of this injury could lead to the development of malocclusion, disc derangement, adhesion and perforation, mandibular growth alterations, and ankylosis ${ }^{1-4}$.

* Assistant Professor of Oral and Maxillofacial Surgery and Head of Oral and Maxillofacial Surgery, Specialized Dental Teaching Hospital, Assistant Professor of Oral and Maxillofacial Surgery Misr University of Science and Technology, Cairo, Egypt

** Assistant Professor of Oral and Maxillofacial Surgery, Faculty of Dentistry, Ain Shams University. 
A few studies have reported the findings of arthroscopy and magnetic resonance imaging (MRI) of the TMJ following acute traumatic mandibular injuries. Most of these studies have involved condylar and subcondylar fractures only. Arthroscopic studies have shown the presence of haemarthrosis and patchy hyperemia of the articular surface secondary to mandibular injury ${ }^{5,6}$. MRI has been shown to provide a more comprehensive evaluation of the intra-articular injuries of the disc, meniscal derangement, joint effusion, and capsular tear $^{7-12}$

\section{Conservative management of condylar} fractures in children usually yields to satisfactory clinical results, However, there use in adult patients is controversial ${ }^{(1,2,3)}$.

This study was performed to investigate the acute TMJ injuries treated with open reduction and internal fixation of unilateral subcondylar fracture using rhombus and two miniplates, and its closed management using magnetic resonance imaging.

\section{PATIENTS AND METHODS}

This study was carried out on 30 adult male patients who presented to the oral and maxillofacial department of a specialized dental teaching hospital in Cairo, Egypt. fractures were secondary to road traffic accidents in all cases. Patients were included if the accident had occurred within the last 10 days. Patients were excluded from the study if they had a previous history of TMJ disorders or joint surgery. Patients with systemic or local pathological conditions that might alter the normal shape, relationships, or structures of the TMJ were also excluded from this study. Furthermore, cases diagnosed with a high intra-capsular fracture and those diagnosed with other facial injuries in addition to the mandibular fractures were excluded from the study. The patients were divided into Three groups based on the method management of the subcondylar fracture mandibular fracture. Group 1 comprised patients who had unilateral condylar fractures treated by open reduction and internal fixation of subcondylar fracture using 3D rhombus plate (Orthomed)

Group 2 patients were treated by open reduction and internal fixation of subcondylar fracture using 2 mini plates. Group 3 Control group were treated patients had a favorable unilateral condylar fracture treated by closed reduction.

TMJs were examined for swelling of the pre-auricular region, tenderness on palpation, deviation during opening, open bite, limitation of mouth opening and maximum mouth opening (MMO), movement of the condylar head, and abnormal sounds from the TMJs, such as clicking or crepitating sounds. The fracture sites and the TMJs were viewed through panoramic radiographs (reverse Towne's view) and computed tomography if indicated. The presence and/or absence of displacement, post-traumatic malocclusion, and loss of posterior vertical height, as well as the surgical and post-surgical procedures performed to restore the occlusion and rehabilitate mandibular function were recorded. MRI of the TMJ was performed in each case within 10 days from the date of injury. The same clinical, radiographic, and MRI examinations were performed at the six month later. All MRI studies were performed using a 1.5 Tesla superconducting magnet (Magnetom H15 SP; Siemens, Erlangen, Germany). Both

TMJs were imaged using a bilateral surface coil 20 $\mathrm{cm}$ in diameter within the surface coil holder. Items that could interfere with the magnetic resonance examination were checked. All patients underwent imaging in the sagittal plane, approximately $1.5 \mathrm{~cm}$ deep to the skin surface anterior to the tragus of the ear. Multiple sagittal slices with an image thickness of $2 \mathrm{~mm}$ were obtained. T1-weighted images were acquired with a spin echo technique (repetition time of $660 \mathrm{~ms}$, echo delay time of $15 \mathrm{~ms}$, and field of view of $200 \mathrm{~mm}$ ). The imaging was repeated in the 
open mouth position, applying the same parameters, in patients who were able to sustain this position.

The surgical treatment of each mandibular fracture (body and angle) was open reduction and internal fixation using semi-rigid 2-mm titanium plates (titanium low profile osteosynthesis system; KLS Martin, Tuttlingen, Germany). In Group 1 are treated with open reduction and internal fixation of fracture with 3D rhombus plate. In group 2 condylar fractures were managed by open reduction and internal fixation with two miniplates. Modified retromandibular approach was the surgical access used in both groups.

In group 3 Group 3, the control group patients who had a unilateral condylar fracture were managed conservatively, which consisted of 2 weeks of intermaxillary fixation (IMF), followed by a period of 2 weeks of IMF with light elastics to restore the occlusion and rehabilitate mandibular function

The statistical analysis was performed using Microsoft Office 2013 (Excel) and IBM SPSS Statistics version 20.0 (IBM Corp., Armonk, NY, USA). The level of significance was set at $\mathrm{P} \leq 0.05$. The $\chi 2$ test was used to compare values between groups.

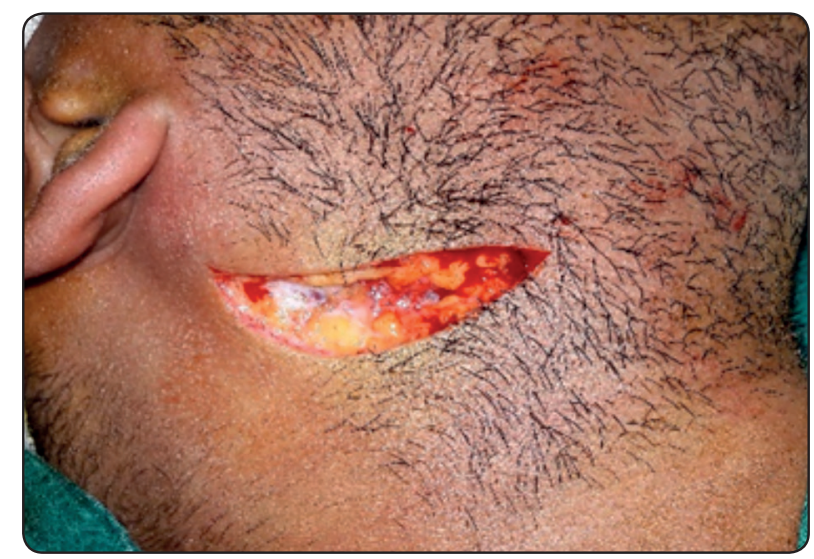

Fig. (1) Showing, retromandibular incision,skin incision parallel and $2 \mathrm{~cm}$ posterior and around angle of mandible.

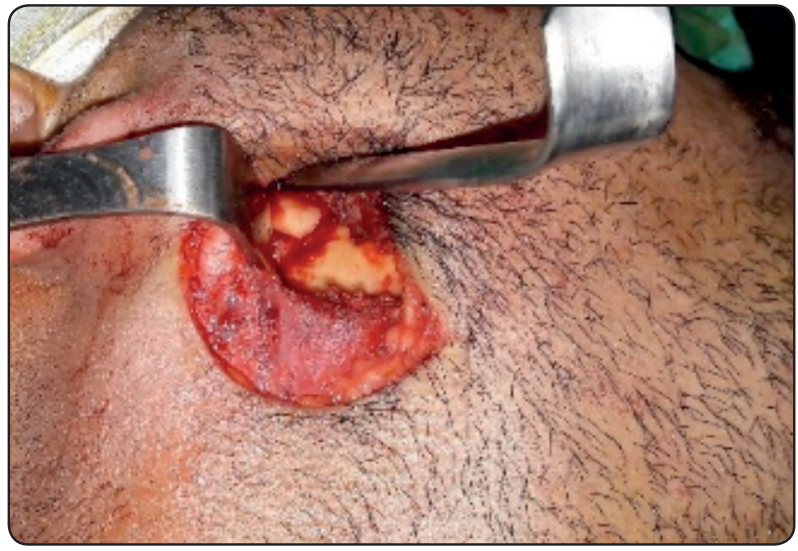

Fig. (2) Showing, undermining of skin and subcutaneous layer, reflection of soft tissues and bone exposure, and application of sigmoid notch retractor.

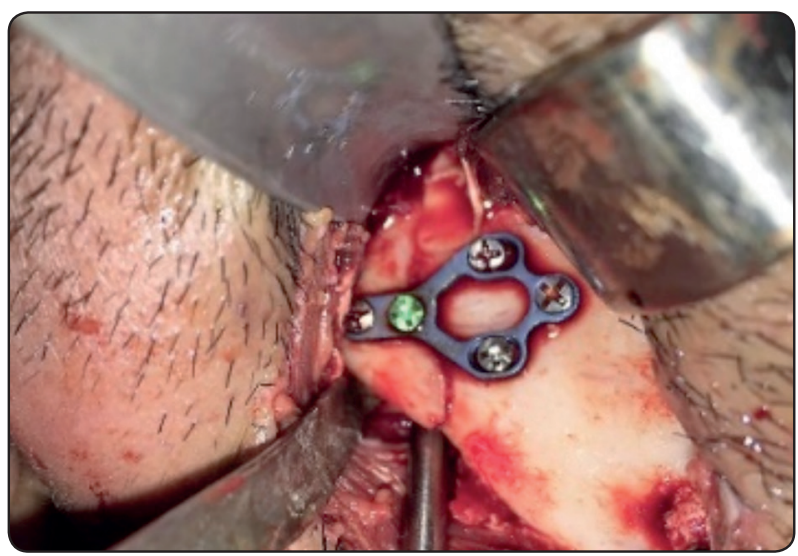

Fig. (3) Showing Fixation of fracture with 3D rhombus plate in group1 patient's.

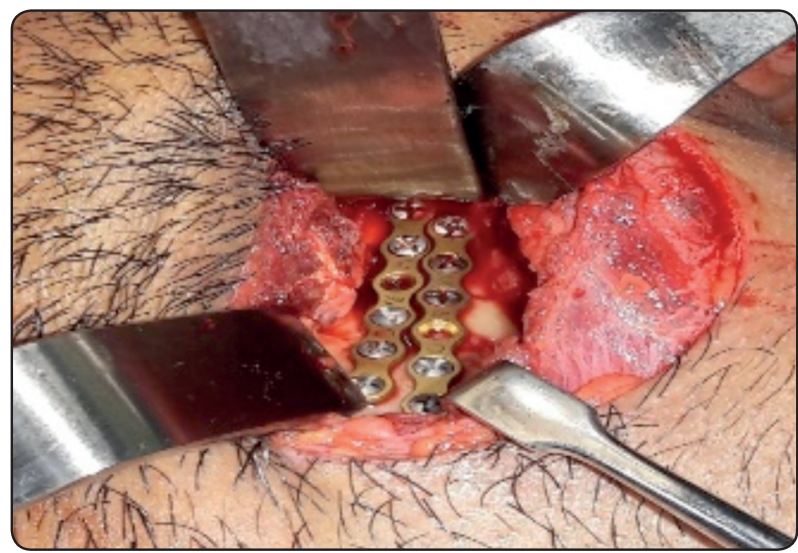

Fig. (4) Showing 2 mini plates in control group 2 patients. 


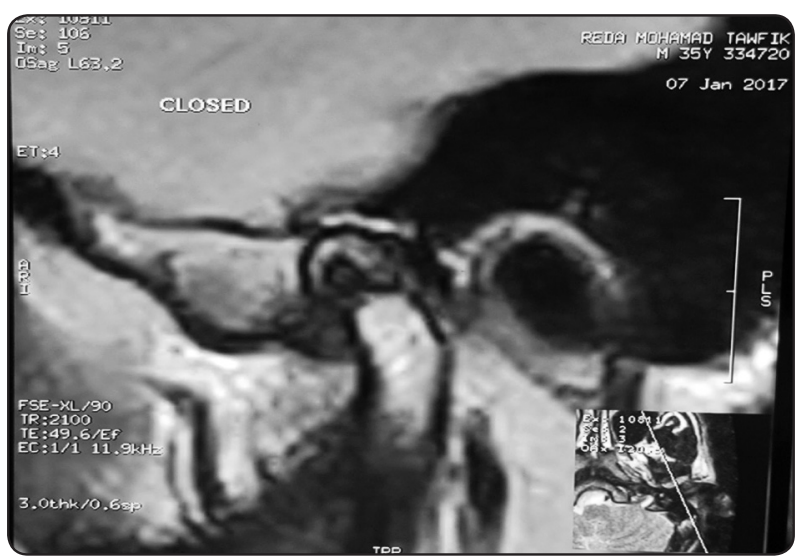

Fig. (5) Showing MRI of the trauma site at the acute stage showing anterior disc displacement

\section{RESULTS}

Thirty patients who fulfilled the selection criteria were studied in each group. The patients ranged in age from 17 to 35 years. Seventeen patients had unilateral subcondylar fracture on the left side, while the rest had it on the right side.

MRI changes in both TMJs following the open versus closed reduction subcondylar fracture, at the acute stage, are described in Table1.

There was no statistically significant differences observed between the three treatment groups for parameters like age, gender, type and side of the fracture, mechanism of injury and incidence of TABLE (1) Showing MRI changes in both groups

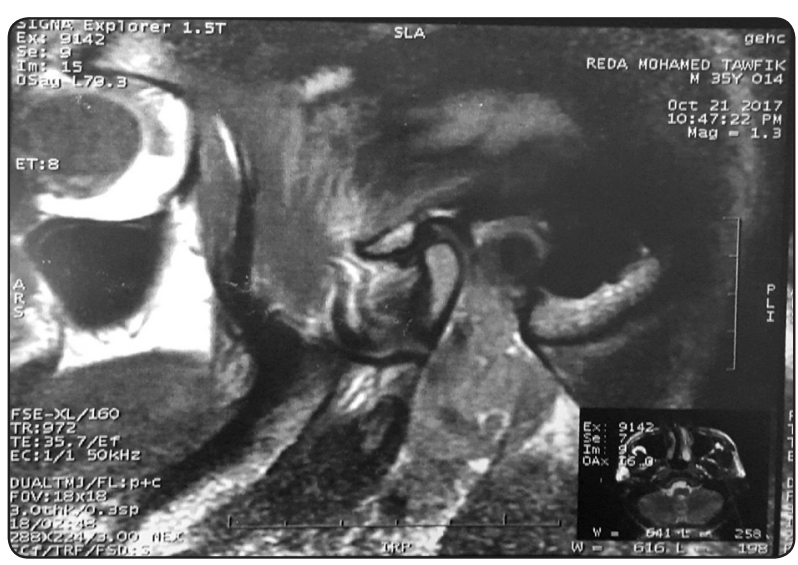

Fig. (6) Showing MRI of the trauma after 6 months follow up showing no change of the disc position after open reduction and internal fixation of the subcondylar fracture.

associated injuries, post-operative occlusion and need for IMF

There was a statistically significant difference between the duration of the surgery between the two open reduction groups and the closed reduction group. Duration of surgery was found to be significantly higher for group 2 . There was a temporary facial nerve weakness noted in 2 cases of group 2 and in two other cases there was a post-operative hematoma. We encountered ipsilateral deviation on opening the mouth and pain on opening the mouth in both groups at the acute stage. In the surgical management group deviation was much improved at the immediate

\begin{tabular}{|l|l|l|}
\hline & Acute stage MRI & Follow up MRI after 6 months \\
\hline Group 1 & $\begin{array}{l}\text { 3 ADD without reduction and joint effusion } \\
\text { 2 ADD without reduction } \\
\text { 5not affected }\end{array}$ & 5ADD without reduction \\
\hline Group 2 & $\begin{array}{l}\text { 2 ADD without reduction and joint effusion } \\
\text { 2ADD without reduction } \\
6 \text { not affected }\end{array}$ & 4 ADD without reduction \\
\hline Group 3 & $\begin{array}{l}\text { 4 ADD without reduction } \\
2 \text { ADD without reduction and joint effusion } \\
1 \text { ADD with reduction } \\
5 \text { not affected }\end{array}$ & 6ADD without reduction \\
\hline
\end{tabular}


TABLE (2) Showing clinical data in groups

\begin{tabular}{|c|c|c|}
\hline & Clinical data at the acute stage & Clinical data 6 months after \\
\hline Group 1 & $\begin{array}{l}6 \text { Limitation of maximum mouth opening (MMO) } \\
2 \text { deviation during opening } \\
7 \text { swelling of the pre-auricular region } \\
7 \text { tenderness on palpation } \\
7 \text { abnormal TMJ sounds }\end{array}$ & $\begin{array}{l}2 \text { Limitation of maximum mouth opening (MMO) } \\
1 \text { deviation during opening } \\
0 \text { swelling of the pre-auricular region } \\
0 \text { tenderness on palpation } \\
5 \text { abnormal TMJ sounds }\end{array}$ \\
\hline Group 2 & $\begin{array}{l}7 \text { Limitation of maximum mouth opening (MMO) } \\
1 \text { deviation during opening } \\
5 \text { swelling of the pre-auricular region } \\
7 \text { tenderness on palpation } \\
3 \text { abnormal TMJ sounds }\end{array}$ & $\begin{array}{l}3 \text { Limitation of maximum mouth opening (MMO) } \\
1 \text { deviation during opening } \\
0 \text { swelling of the pre-auricular region } \\
0 \text { tenderness on palpation } \\
4 \text { abnormal TMJ sounds }\end{array}$ \\
\hline Group 3 & $\begin{array}{l}5 \text { Limitation of maximum mouth opening (MMO) } \\
3 \text { deviation during opening } \\
6 \text { swelling of the pre-auricular region } \\
7 \text { tenderness on palpation } \\
3 \text { abnormal TMJ sounds }\end{array}$ & $\begin{array}{l}2 \text { Limitation of maximum mouth opening (MMO) } \\
2 \text { deviation during opening } \\
0 \text { swelling of the pre-auricular region } \\
0 \text { tenderness on palpation } \\
3 \text { abnormal TMJ sounds }\end{array}$ \\
\hline
\end{tabular}

post-operative follow up, although after 6 months the difference was not statistically significant. In all groups we could achieve a post-operative mouth opening $>35 \mathrm{~mm}$ after follow up in $90 \%$ of cases. Group 2 had an inconspicuous scar in 3 cases which was camouflaged. There was a no statistically significant difference between the MRI findings in all groups, The different treatment modalities did not affect the final outcome on the TMJs, hence the most important factor was the magnitude and, and the direction of force that cause the injury itself ; rather than the management procedure.

\section{DISCUSSION}

Mandibular subcondylar fractures are among the commonest facial bone fractures ; however its management remained controversial. Both surgical and non-surgical treatment have been used. In closed management actual reduction of fractures does not occur and hence the term closed reduction is not accepted. closed management includes stabilizing the fractures and adapting the musculature to reestablish proper occlusion.
Absolute indication for open reduction has been agreed ; these includes dislocation into the middle cranial fossa or external auditory canal, lateral extra-capsular displacement, open joint wound with foreign body or gross contamination, and most importantly if adequate occlusion could not be obtained ${ }^{(13)}$. Ellis and Throckmorton ${ }^{(14)}$ demonstrate that their prime indication for open reduction is when the patient has combination of comminuted mobile maxillary fracture that requires ORIF, in addition to condylar fracture(s). others includes bilateral condylar fractures ${ }^{(15)}$, and when stability of occlusion is limited ( e.g., less than 3 teeth per quadrant, gross periodontal disease, skeletal abnormality) $)^{(16)}$. Open reduction is contraindicated the condylar head is fractured, in medical condition or systemic injury add undo risk to general anesthesia ${ }^{(15)}$. The management of these fractures in children is usually closed reduction (17) despite encountered postsurgical radiographic abnormalities,

Condylar neck and subcondylar fractures are the most common mandibular fractures in adults. 
Subcondylar fractures are below the condylar neck. Fractures here enter the sigmoid notch and may be considered "high or low," depending on the site of exit of the posterior extension of the fracture. Most subcondylar fractures are also treated conservatively, using a closed approach to avoid complications. Subcondylar fractures offer sufficient bone stock for ORIF. ${ }^{(22)}$

The use of MRI provides an insight into the damage caused to the TMJ secondary to mandibular fracture. The results of the present study showed no direct correlation between TMJ pain and the presence of MRI changes. There is debate about whether closed reduction or open reduction and internal fixation is the ideal treatment for fractures of the mandibular condyle, as reported in metaanalysis reviews ${ }^{(23,24)}$. In 2016 Nabil ${ }^{(25)}$ evaluated the effect the effect of different mandibular fractures on the temporomandibular joint using magnetic resonance imaging after five years, he found that trauma caused more delayed TMJ derangement on the non-fractured side than on the fractured side of the mandible. Disturbances of the TMJ on the side of the fracture develop during both the acute stage and follow-up. In the present study TMJ changes was statistically insignificant between all groups. In conclusion, from the present study, we found no correlation between the clinical assessment and magnetic resonance findings. The different treatment modalities did not affect significantly the temporomandibular joint anatomical structure, hence the most important factor was the magnitude and, and the direction of force that cause the injury itself ; rather than the management procedure.

\section{REFERENCES}

1. Laskin DM. Role of meniscus in the etiology of posttraumatic temporomandibular joint ankylosis. Int $\mathrm{J}$ Oral Surg 7: 340-345; 1978.

2. Ryan D, Ahmed S, Harris M. Arthrotomography and the surgical correction of temporomandibular joint disorders. Br J Oral Maxillofac Surg 28: 228-233; 1990.
3. Zhang Y, He DM. Clinical investigation of early posttraumatic temporomandibular joint ankylosis and the role of repositioning discs in treatment. Int J Oral Maxillofac Surg 35: 1096-1101; 2006.

4. Harkins SJ, Marteney JL. Extrinsic trauma: a significant precipitating factor in temporomandibular joint dysfunction. J Prosthet Dent 54: 271-272; 1985.

5. Goss AN, Bosanquet AG. The arthroscopic appearance of acute mandibular trauma. J Oral Maxillofac Surg 48: 780-783; 1990.

6. Jones JK, Van Sickels JE. A preliminary report of arthroscopic findings following acute condylar trauma. J Oral Maxillofac Surg 49: 55-60; 1991.

7. Choi B. MRI of temporomandibular joint after functional treatment of bilateral condylar fractures in adults. Int $\mathrm{J}$ Oral Maxillofac Surg 26: 344-3471997.

8. Oezmen Y, Mischkowaski R, Lenzen Y, Fischbach R. MRI examination of temporomandibular joint and functional results after conservative and surgical treatment of mandibular condyle fractures. Int J Oral Maxillofac Surg 27: 33-37; 1998.

9. Sullivan S, Banghart P, Anderson Q. Magnetic resonance imaging assessment of acute soft tissue injuries of the temporomandibular joint. J Oral Maxillofacial Surg 53: 763-766; 1995.

10. Takaku S, Yosjida M, Sano T, Toyoda T. Magnetic resonance images in patients with acute traumatic injury of the temporomandibular joint: a preliminary report. $\mathrm{J}$ Craniomaxillofac Surg 24: 173-177; 1996.

11. Gerhard S, Ennemoser T, Rudisch A, Emshof R. Condylar injury: magnetic resonance imaging findings of temporomandibular joint soft tissue changes. Int J Oral Maxillofac Surg 36: 214-218;2007.

12. Dwivedi A, Tripathi R, GuptaP,Tripathi S, Garg S.Magnetic resonance imaging evaluation of temporomandibular joint and associated soft tissue changes following acute condylar injury. J Oral Maxillofac Surg 70: 2829-2834; 2012.

13- Zide MF,Kent JN. Indications for open reduction of mandibular condyle fractures. J oral maxillofac Surg. 41(2):89-98; 1983.

14- Ellis E, and Throckmorton GS. Treatment of condylar process fractures; biological consideration. J Oral Maxillofac. Surg. 63;115-134; 2005. 
15- Tomingaga K, Habu M, Khanal A. Biomechanical evaluation of different types of rigid internal fixation techniques for subcondylar fractures. J Oral Maxillofasc. Surg. 64 (10):1510-1516; 2006.

16- Hauge RH, and Assael LA. Outcomes of open versus closed treatment of mandibular subcondylar fractures. J Oral Maxillofacial surg. 59:370-375; 2001.

17- Theologie-Lygidakis N, Chatzidimitriou K, Tzerbos F,and Gouzioti A, Iatrou 1 Nonsurgical management of condylar fractures in children: A 15-year clinical retrospective study. Journal of Cranio-Maxillo-Facial Surgery 44: 85-93; 2016.

18- Ghasemzadeh A, Mundinger GS, Swanson EW, et al. Treatment of pediatric condylar fractures: a 20-year experience. Plast Reconstr Surg 136(6):1279-1288; 2015.

19- Lindahl L Condylar fractures of the mandible. IV. Function of the masticatory system. Int J Oral Sur6(4): 195-203; 1977.

20- Zou ZJ, Wu WT, Sun GX, Zhu XP, Zhang KH, Wu QG, $\mathrm{Su}$ LD, Lin JX. Remodelling of the temperomandibular joint after conservative treatment of condylar fractures. Dentomaxillofac Radio1981987-91 :(2)16 ..

21- Manisali M, Amin M, Aghabeigi B, Newman L Retromandibular approach to the mandibular condyle: A clinical and cadaveric study. Int J Oral Maxillofac Surg; 32(3): 253-256; :2003

22- Hidding J, Wolf R, Pingel D: Surgical versus non-surgical treatment of fractures of the articular process of the mandible. J Craniomaxillofac Surg 20:345; 1992.

23- Kyzas PA, Saeed A, Tabbenor O. The treatment of mandibular condylar fractures: a meta-analysis. J Craniomaxillofac Surg 40:438-52; 2012.

24- Chrcanovic BR. Surgical versus nonsurgical treatment of mandibular condylar fractures:- a meta-analysis. Int J Oral Maxillofac Surg 44:158-79; 2015.

25- Y. Nabil: Evaluation of the effect of different mandibular fractures on the temporomandibular joint using magnetic resonance imaging: five years of follow-up. Int. J. Oral Maxillofac. Surg. 45: 1495-1499; 2016. 